\title{
ASISTENCIA PRIORITARIA DE LA CONDICIÓN DE LA PERSONA CON DISCAPACIDAD Y EL PRINCIPIO DE PRIORIDAD DEL REGISTRO DE BIENES INMUEBLES
}

\section{ARTÍCULO ORIGINAL}

NETO, Alexandre Moura Lima ${ }^{1}$, AGUAIR, Alessandra Anchieta Moreira Lima de ${ }^{2}$, NETO, Haroldo Corrêa Cavalcanti ${ }^{3}$

NETO, Alexandre Moura Lima. AGUAIR, Alessandra Anchieta Moreira Lima de. NETO, Haroldo Corrêa Cavalcanti. Asistencia prioritaria de la condición de la persona con discapacidad y el principio de prioridad del registro de bienes inmuebles. Revista Científica Multidisciplinar Núcleo do Conhecimento. Año 06, Ed. 09, Vol. 03, págs. 45-63. Septiembre 2021. ISSN: 2448-0959, Enlace de acceso: https://www.nucleodoconhecimento.com.br/ley/asistencia-prioritaria, DOI: 10.32749/nucleodoconhecimento.com.br/ley/asistencia-prioritaria

\section{RESUMEN}

El presente estudio tiene como objetivo analizar el aparente conflicto entre el cuidado prioritario de la condición de la persona con discapacidad y el principio de prioridad del registro de bienes inmuebles, es decir, si esta garantía legal, otorga prioridad a la persona con discapacidad al anotar derechos en notarías. En cuanto a la metodología utilizada, cabe destacar que, en cuanto a los fines de este estudio, este estudio se clasifica como descriptivo y explicativo y, en cuanto a los medios, se clasifica como bibliográfico, utilizando materiales como libros, artículos, revistas e informes sobre el tema. La investigación también se caracteriza por ser un enfoque

\footnotetext{
${ }^{1}$ Máster en Cultura y Sociedad de la Universidad Federal de Maranhão (UFMA). ORCID: https://orcid.org/00000002-7232-8449

${ }^{2}$ Tiene una Maestría en Medio Ambiente del Programa de Postgrado en Medio Ambiente de la Universidade Ceuma. ORCID: https://orcid.org/0000-0003-4017-1579

${ }^{3}$ Especialización en Derecho Inmobiliario. ORCID: https://orcid.org/0000-0003-1746-1965
}

RC: 97615

Disponible: https://www.nucleodoconhecimento.com.br/ley/asistencia-prioritaria 
cualitativo. Se pretendía demostrar que la persona con discapacidad tiene el derecho garantizado por la Ley 13.143/2015 a ser atendida de manera rápida, efectiva e individual, incluso en el Registro de Registros Inmobiliarios, pero no goza de privilegios en vista de la prioridad registral en vista del principio de prioridad registral. De las decisiones tomadas por los tribunales registrados de São Paulo, como resultado, se encuentra que la disposición específica de la Ley № 6.015/1973 prevalece en relación con el derecho de atención prioritaria de ciertos públicos, la Ley $13.143 / 2015$, ya que es un derecho material de prioridad, y se entiende que otorgar atención prioritaria fuera de los requisitos del art. 186 de la Ley № 6.015/1973, se entiende que otorga atención prioritaria fuera de los requisitos del Art. 186 de la Ley № 6.015/1973, representaría una afrenta innegable a los dictados jurídicos, lo que comprometería el servicio del derecho a la igualdad, premisa también del Estatuto de las personas con discapacidad.

Palabras clave: Estatuto de la Persona con Discapacidad, Registro de Bienes Inmuebles, Principio de Prioridad.

\section{INTRODUCCIÓN}

La vida cotidiana de las personas con necesidades especiales es compleja, considerando sus limitaciones y la falta de preparación de la sociedad para recibirlas, tanto en relación a la infraestructura como a la mentalidad de los individuos, así, terminan siendo excluidos socialmente, actividades como divertirse, estudiar e ir a trabajar, que son tareas sencillas y rutinarias se convierten en un reto a enfrentar.

Como destaca Carlos Henrique Ribeiro da Silva (2008), la falta de tolerancia entre los diferentes, a lo largo de la historia, hizo que las minorías siempre fueran tratadas de manera relativamente agresiva y confusa, etiquetando, segregando, discriminando y excluyendo a quienes se desviaban de la norma, que se forma a

RC: 97615

Disponible: https://www.nucleodoconhecimento.com.br/ley/asistencia-prioritaria 
partir de un modelo hegemónico. Otro factor muy común, originado por la falta de comprensión sobre las diferencias entre las personas está en la persona considerada diferente, que asume actitudes muy particulares como el autocastigo, el aislamiento y la agresividad. Así, se cree que la falta de tolerancia con las diferentes tiene raíces históricas, aunque mucho ya ha avanzado en relación al tema.

Durante mucho tiempo en Brasil la persona con discapacidad fue considerada incapaz, con los cambios sociales este hecho fue siendo modificado y estas personas comenzaron a ser reconocidas como sujetos de derecho y capaces de tomar sus decisiones, tanto que en 2015, la Ley oㅜ 13.146 cambió el Código Civil, instituyendo el Estatuto de las personas con discapacidad. Según Lago (2016), la publicación de este Estatuto tuvo como objetivo superar el bienestar y superar las barreras para las personas con discapacidad, como premisa para garantizar el derecho a la dignidad, el civismo y la plena participación en la sociedad. Sin embargo, según el autor, la prioridad otorgada a estas personas por el Estatuto entra en conflicto con el principio de prelación en el registro de bienes inmuebles en virtud de la Ley 6.015/1973 y el Código Civil en orden de presentación de los títulos, que es el foco de este estudio. Así, se buscará discutir en este ensayo sobre la prioridad en el Estatuto de las personas con discapacidad frente a la prioridad descrita en la Ley de Registros Públicos (Ley 6.015/73). Teniendo como guía la pregunta: ¿si la persona con discapacidad, en vista de la persona con discapacidad, goza de privilegios frente al otro, en la consagración de la prioridad registral?

El principio de prelación, en derecho inmobiliario, es el hecho de que siempre tendrá prioridad realizar los trámites registrals del título presentado previamente ante la oficina del registro de bienes raíces. Según el art. 186 de la Ley de Registros Públicos (Ley 6.015/73), "el número de orden determinará la prioridad del título, y esta es la preferencia de los derechos reales, incluso si la misma persona presenta más de un título simultáneamente", de modo que la prioridad se determinará para quien primero presente el título en la oficina de registro de bienes raíces. $Y$ en el

RC: 97615

Disponible: https://www.nucleodoconhecimento.com.br/ley/asistencia-prioritaria 
protocolo de la notaría, "todos los títulos tomarán el número de orden que compita con ellos en base a la rigurosa secuencia de su presentación" (art. 182).

Durante los últimos siglos, el sistema de registro brasileño ha sido constantemente modificado a través de una legislación que tiene como objetivo monitorear la evolución de la sociedad en su conjunto, permitiendo la seguridad, publicidad y eficacia de las transacciones inmobiliarias tanto para quienes participan en ella como para aquellos que están interesados en ella. Según Lima (2011) tanto la actividad notarial como la registral actúan como medio de pacificación social, garantizando la publicidad, autenticidad, seguridad y eficacia de los actos jurídicos de manera preventiva.

Es importante destacar que aunque las actividades notariales y registrales están asociadas, no deben confundirse. Benício (2005) aclara que esta diferencia se puede ver cuando se habla de la función de registrador y notario (notario), donde el primero actúa con el objetivo de legitimar y publicitar los actos, mientras que el segundo engloba el asesoramiento en sus funciones con posterior legitimación, autenticidad y formalización de actos jurídicos. Aún diferenciando las dos actividades, el autor afirma que el notario tiene como función predominante la seguridad dinámica[4], mientras que el registrador la seguridad estática ${ }^{[5]}$, en definitiva, mientras que el notario busca salvaguardar el actum (acta), el registrador se limita a publicar el dictamen (said).

Las actividades realizadas bajo el derecho notarial y los escaneos registrales deben ser vistos en su relevancia social, como señala Ceneviva (2008), su importancia se debe al alcance de los actos, que implica desde el nacimiento hasta la muerte, registrar y dar publicidad a todos los actos jurídicos realizados por los ciudadanos durante sus vidas, como el matrimonio, el divorcio, el compartir, inventarios, contratos de compraventa, entre otros, regularizando todas las acciones realizadas.

RC: 97615

Disponible: https://www.nucleodoconhecimento.com.br/ley/asistencia-prioritaria 
Por lo tanto, estas son actividades directamente relacionadas con la vida cotidiana de los individuos.

Se destaca la relevancia social de este estudio, considerando que involucra a una minoría de la población que necesita atención en el cumplimiento de sus derechos, y puede aclarar mejor sobre posibles conflictos con el principio de prioridad en el registro de bienes inmuebles, así como la relevancia profesional y académica, ya que muchas siguen siendo las controversias que giran en torno al tema, sin embargo, con pocos estudios realizados y publicados sobre el problema en cuestión, por lo tanto, esta investigación sigue estando justificada.

En cuanto a la metodología utilizada, se destaca, con base en Maria Cecilia de Souza Minayo (2007), que respecto a los propósitos de este estudio se clasifica como descriptivo y explicativo y, en cuanto a los medios, se clasifica como bibliográfico, utilizando materiales accesibles al público como libros, artículos, revistas e informes sobre el tema. La investigación también se caracteriza por ser un enfoque cualitativo puro. Se tomó como base lo que otros autores escribieron, pudiendo entender diferentes puntos de vista sobre el tema, dirigiendo el estudio de la mejor manera para hacer que la investigación sea confiable.

En este contexto, como se ha señalado anteriormente, el presente estudio tiene como objetivo analizar el conflicto entre el cuidado prioritario de la condición de las personas con discapacidad y el principio de registro prioritario de bienes inmuebles.

\section{PERSONAS CON DISCAPACIDAD EN UN CONTEXTO HISTÓRICO}

Desde el principio de los tiempos hay registros de personas con necesidades especiales. La idea cultural de discapacidad, impotencia y dependencia de las personas con dificultades motoras atraviesa culturas, sociedades, grupos socioculturales, religiones y prácticas sociales. La ruptura de la expectativa de los padres con el nacimiento de niños afectados por algún tipo de problema motor, la

$\mathrm{RC}: 97615$

Disponible: https://www.nucleodoconhecimento.com.br/ley/asistencia-prioritaria 
adquisición de alguna secuela de enfermedades o accidentes, son ciertamente eventos difíciles y se han experimentado en muchas culturas de manera atípica (GUGEL, 2011).

Según Débora Fazolin Koyama (2017) las personas con discapacidad física siempre se han enfrentado a diversas situaciones de exclusión y segregación ante la sociedad, en el período de la antigua Grecia esto fue especialmente retratado por la ciudad-estado de Esparta, ya que los niños que nacían con algún tipo de discapacidad eran considerados como inútiles para esa sociedad y arrojados a un abismo.

Débora Fazolin Koyama (2017) dice que a lo largo de la historia las personas con discapacidad siempre han librado una gran lucha por la vida y por conquistar su espacio en la sociedad, ya que la cultura impuesta por la sociedad de las personas siempre las ha marginado y actuado de manera excluyente con estas personas.

Las personas con discapacidad comenzaron a tener algunos de sus derechos reconocidos solo en la Declaración Universal de los Derechos Humanos y a partir de entonces, se dio una patada a lo que se convertiría en la estandarización de principios fundamentales para estas personas, a partir de ese momento surgió: el principio de la dignidad de la persona humana, principio de igualdad, entre otras normas protectoras. (KOYAMA, 2017)

El antiguo Egipto, según Clemente (2015, p. 34) era conocido como la "Tierra de los Ciegos porque su gente se vio constantemente afectada por infecciones oculares, lo que resultó en ceguera". Por otro lado, hay registros históricos de que en lugares de la antigua Grecia y Esparta, los niños con deformidades eran abandonados en los bosques o arrojados desde las gargantas.

Las leyes romanas de la antigüedad no protegían a las personas con discapacidad, por el contrario, legitimaban a los padres para matar a sus hijos, a través de la

$\mathrm{RC}: 97615$

Disponible: https://www.nucleodoconhecimento.com.br/ley/asistencia-prioritaria 
práctica del ahogamiento, abandonados en cestas en el río Tíber, o en otros lugares sagrados, algunos de los cuales estaban expuestos y utilizados como entretenimiento en circos. Estudios realizados por Lourenzetto (2006) confirman cómo en los primeros cuatro siglos de la era cristiana, no hubo una expresión significativa que favoreció la inserción de las personas con discapacidad como sujetos de dignidad y derechos.

En la antigüedad, hay pocos registros de la relación de la sociedad con los discapacitados en la vida cotidiana. A través de pasajes bíblicos se puede percibir la discriminación que existía en la época contra las personas con discapacidad, pues siempre son mencionadas como mendigos o rechazadas por la comunidad, es decir, vivían al margen de la convivencia social y comunitaria. Muchos creían que estas personas eran castigadas por los dioses (Lourenzetto, 2006, p. 3).

En la Edad Media, la discapacidad se consideraba un fenómeno metafísico, determinado por la posesión demoníaca o como castigo de dios. Tales personas eran vistas como "poseedoras de un mal debido al pacto con el diablo", justificación utilizada para legitimar socialmente el uso extremo de la fogata como castigo (MAINIERI; ROSA, 2012).

Se creía que tal práctica hacía posible humillar y ganar contra el supuesto enemigo que tenía que ser derrotado. Para Maria Aparecida Gugel (2011) además de dar a las personas con discapacidad poderes especiales de brujos, los niños que sobrevivieron fueron separados de sus familias y casi siempre ridiculizados.

Marcella Lourenzetto (2006) hace referencias en documentos papales, que en el caso de una persona con discapacidad mental huir de su razón, era considerado un ser diabólico, pasando a ser perseguido, torturado y exterminado. En el siglo 15, tales individuos aún no eran percibidos como seres humanos.

En estos ejemplos, es explícito cómo la segregación y el fatalismo afectaron a las personas con problemas de ceguera y a cualquier otra que huyera de los estándares

RC: 97615

Disponible: https://www.nucleodoconhecimento.com.br/ley/asistencia-prioritaria 
establecidos como normales (BIANCHETTI; FREIRE, 2007). La pena de amputación también se utilizó como control y castigo de los traidores en las Constituciones Romanas del emperador León III, un proceso que prevaleció en el Imperio Romano y Oriente.

El razonamiento introducido noblezamente en el período de la Inquisición adoptó la práctica de quemar a las personas que traían en su cuerpo alguna diferencia considerada no normal, o que presentaban ideas divergentes del status quo o que se comportaban de una manera considerada inadecuada. Por esta razón, en las declaraciones de la inquisición y en las justificaciones de la Iglesia no hay declaraciones de que ella haya quemado a la gente. Como afirman Lucídio Bianchetti e Ida Maria Freire (2007, p. 33), la Iglesia enunció tal acción como [...] "purificación por llamas". Otra explicación de la existencia de ciegos, mudos, paralíticos, locos y leprosos fue que estos fueron concebidos como:

[...] los instrumentos de Dios para advertir a hombres y mujeres sobre comportamientos apropiados o para brindarle la oportunidad de hacer caridad. Por lo tanto, la desgracia de algunos proporcionó medios de salvación a otros. (BIANCHETTI; FREIRE, 2007, p. 33).

Según Maria Aparecida Gugel (2011), el proceso de las personas con discapacidad será reconocido como personas de dignidad y valor que llegaron con los primeros hospitales de caridad. Para el autor, entre 1214 y 1270, el rey Luís IX fundó el primer hospital para ciegos víctimas de las Cruzadas. La construcción de nuevas concepciones sobre la discapacidad sólo fue históricamente posible en el siglo XVI, cuando los avances tecnológicos y científicos permitieron la aparición de distintas concepciones en medicina.

Fue solo en el siglo 16, con los avances científicos en el campo de la medicina, que aparecieron las primeras declaraciones disonadas sobre el tratamiento de los discapacitados (GUGEL, 2011).

RC: 97615

Disponible: https://www.nucleodoconhecimento.com.br/ley/asistencia-prioritaria 
La mayoría de los hombres y mujeres se limitaban a vivir su vida cotidiana, de una manera miserable, involucrados con la producción para la subsistencia. Con el predominio gradual de la producción orientada al mercado, la posibilidad de acumulación, el desarrollo de una ciencia y nuevas tecnologías, obtiene un dominio relativo sobre la naturaleza. Con este proceso se crearon las condiciones materiales, sociales y culturales para la construcción de procesos emancipadores que permitan el paso de la esfera de necesidad por la libertad.

No fue hasta el siglo 16 que otro proceso histórico diferente de la situación histórica anterior fue posible. Con los avances en la medicina que se produjeron en el siglo 17, la discapacidad física se entendió como un objeto de estudio de la práctica médica. El proceso de medicalización de las deficiencias implicaba en la crítica de las visiones históricamente presentes, que en cada hombre presidía un estado mórbido, la presencia de demonios malignos que influían en la salud y la enfermedad (BIANCHETTI; FREIRE, 2007).

Las explicaciones metafísicas de la esfera religiosa se confrontan con el paradigma científico positivista, de modo que la visión teológica sobre la diferencia pierde fuerza, pero influye en las bases teóricas para una interpretación organicista. En el siglo 17, se desató un gran claustro de todos aquellos que no participan en la Razón Universal, que estaba emergiendo. El que mostraba ausencia de razón en cualquiera de sus formas, como razón lógica, política, moral estaba enclaustrado (BIANCHETTI; FREIRE, 2007).

Fue solo a partir de mediados del siglo 19 que comenzaron a surgir las primeras instituciones para el cuidado de personas con discapacidades físicas. Durante mucho tiempo, estas personas fueron consideradas solo como pacientes que necesitaban atención especial y estas fueron vistas como personas con bajo potencial y con numerosas limitaciones. En Brasil, en el mismo período, el Instituto Imperial de los Ciegos y el Instituto Imperial de sordomudos fueron establecidos por

$\mathrm{RC}: 97615$

Disponible: https://www.nucleodoconhecimento.com.br/ley/asistencia-prioritaria 
orden de D. Pedro II, que fue establecido por orden de D. Pedro II y el Instituto Imperial de sordomudos, un hecho considerado como una de las primeras actitudes brasileñas para la integración de los discapacitados en la sociedad (SOUSA, 2012).

Sin embargo, la creación de dispositivos de clausura también generó procesos de segregación del entorno social, dando como resultado, la construcción de lo que Erving Goffman (2008, p.13) define como estigma, "[...] un tipo especial de relación entre atributo y estereotipo", entendiéndose en el contexto de las relaciones humanas y no sustantivas. "Un atributo que estigmatiza a alguien puede confirmar la normalidad de los demás".

El tema de la discapacidad toma otro foco debido a la observación del cambio de paradigma, asentido en la década de 1970, del siglo pasado, se abogan por acciones integradoras con el fin de favorecer la presencia/inserción de las personas con discapacidad en las mismas esferas sociales que las demás. Sin embargo, esta posibilidad aparece como algo utópico en su funcionalidad real, pues como explica Erving Goffman (2008, p. 134):

La situación especial del estigmatizado es que la sociedad le dice que es miembro del grupo más amplio, lo que significa que es un ser humano normal, pero también que es hasta cierto punto, "diferente", y que sería absurdo negar esta diferencia. La diferencia en sí misma deriva de la sociedad, porque en general, antes de que una diferencia sea importante, debe ser conceptualizada colectivamente por la sociedad en su conjunto.

Así, la inserción de este público en los diferentes ámbitos sociales es cada año mayor, aunque las instalaciones físicas, la oferta de material y la formación de profesionales para atender a personas con necesidades especiales siguen siendo precarias, centrando este estudio en los derechos de estos ciudadanos, más concretamente en la integración, inclusión e igualdad, basados en el principio básico de la dignidad de la persona humana.

RC: 97615

Disponible: https://www.nucleodoconhecimento.com.br/ley/asistencia-prioritaria 


\section{DERECHOS HUMANOS CON ÉNFASIS EN LAS PERSONAS CON DISCAPACIDAD}

Los derechos humanos con énfasis en las personas con discapacidad, además de la dignidad de la persona humana y la igualdad, deben destacar el derecho a la movilidad y a la ciudad, así como la educación y la salud, dado que son factores cruciales para garantizar la inclusión social de estas personas. A lo largo del proceso evolutivo de la civilización humana se realizaron la búsqueda de derechos que iban desde la locomoción hasta la circulación en entornos públicos y privados de forma independiente.

Históricamente, las personas han sido irrespetadas y totalmente excluidas de la vida social, especialmente del contexto social y esto se basaba en las ideas que tenían sobre el ser humano y la sociedad que se inculcaron en los individuos formando un modelo mental que se asienta en este y ya no desaparece. Simplemente transforma (LOPES et al., 2009, p. 29).

La perspectiva de los derechos de los ciudadanos históricamente alcanzada ha traído la idea de integración, inclusión, igualdad como una forma de hacer frente a los procesos de exclusión social, discriminación y estigmatización. Este proceso es fundamental, como las aceras que garantizan el derecho a entrar y salir de cualquier ciudadano de la ciudad donde vive.

En Brasil, este proceso implicó el reconocimiento del derecho a la accesibilidad. En la Constitución Federal, capítulo VII, art. 227 se dispone la "facilitación del acceso a bienes y servicios colectivos, con la eliminación de prejuicios y obstáculos arquitectónicos", con lo que se cuenta con normas que garantizan la construcción de la adecuación de lugares, edificios públicos y transporte público. (NOGUEIRA, 2010, p. 51). En 1981, por ejemplo, las Naciones Unidas - ONU reconocieron en una convención el año internacional de las personas con discapacidad. En 1989, estos derechos fueron modificados por la Ley No. 7.853, cuyo propósito es establecer "la protección judicial de los intereses colectivos o difusos de estas personas, disciplina

RC: 97615

Disponible: https://www.nucleodoconhecimento.com.br/ley/asistencia-prioritaria 
el desempeño del Ministerio Público, define los delitos y proporciona otras medidas" (BRASIL, 1989). La misma ley determina el cumplimiento de la aplicación de las normas por parte de los municipios con el fin de promover la funcionalidad de los edificios y la vía pública para los discapacitados.

Por último, la Ley Federal No. 10.098 de 19 de diciembre de 2000[6], posteriormente reglamentada por el Decreto No. 5.296 de 2 de diciembre de 2004[7], por la que se normaliza la cuestión de la accesibilidad como meta de adaptación e institución de acceso. Hasta la fecha, sin embargo, esta ley no se ha implementado, ya que no se contemplaron plenamente elementos como el acceso a los edificios públicos, la permanencia y el uso disponible en estos edificios, como la educación y la salud. Las aceras son el retrato de la sociedad excluyente, por lo que es necesario resolver problemas de emergencia, como agujeros en las calles, automóviles en las aceras que interrumpen la movilidad, estandarización de rampas, pasamanos, pasarelas, baños públicos y señalización especial para minimizar los problemas de accesibilidad (COELHO, 2010).

En este sentido, el derecho a la accesibilidad es un factor indispensable no solo para quienes tienen algún tipo de discapacidad o movilidad reducida, sino para la sociedad en su conjunto, pues en base al principio de igualdad todos son iguales ante la ley y gozan de los mismos derechos de ir y venir, la educación, el ocio, vivienda, turismo y cultura. Según la Declaración de los Derechos de las Personas con Discapacidad, adoptada en una Asamblea General de las Naciones Unidas (ONU) en 1975, proclama entre otras resoluciones que: "Las personas con discapacidad tienen derecho a medidas destinadas a empoderarlas para que se vuelvan lo más seguras de sí mismas posible".

La Carta Mundial del Derecho a la Ciudad aprobada en el Foro Social de las Américas en Quito, el Foro Urbano Mundial en Barcelona en 2004 y el Quinto Foro Social Mundial de Porto Alegre en 2005 establece compromisos entre los gobiernos

RC: 97615

Disponible: https://www.nucleodoconhecimento.com.br/ley/asistencia-prioritaria 
y la sociedad civil organizada para promover ciudades basadas en los principios de solidaridad, libertad, igualdad, justicia social y dignidad.

El derecho a la ciudad se define en la Carta como: "El disfrute equitativo de las ciudades dentro de los principios de sostenibilidad, democracia y justicia social [...] es interdependiente de todos los derechos internacionalmente reconocidos". La ciudad se concibe en este documento como "un espacio colectivo culturalmente rico y diversificado que pertenece a todos los ciudadanos" (CARTA MUNDIAL DO DIREITO À CIDADE, 2004, p. 2). En cuanto a la protección especial de los grupos y personas vulnerables, la Carta de la Ciudad establece:

Las ciudades a través de políticas de afirmación positiva a los grupos vulnerables deben superar los obstáculos políticos, económicos y sociales que limitan la libertad, la equidad y la igualdad de los ciudadanos, y que impiden el pleno desarrollo de la persona humana y la participación efectiva en la organización política, económica, cultural y social de la ciudad (CARTA MUNDIAL DO DIREITO À CIDADE, 2004, p. 3).

En cuanto a la movilidad urbana, el artículo 13 establece:

1. Las ciudades garantizan el derecho a la movilidad y circulación en la ciudad a través de un sistema y transporte público accesible a todas las personas según un plan de desplazamiento urbano y de larga distancia y, en base a los medios de transporte adecuados, las diferentes necesidades sociales (género, edad, discapacidad) y medioambientales, con precios adecuados a los ingresos de los ciudadanos. Se fomentará el uso de vehículos no contaminantes y se reservarán zonas peatonales de forma permanente a determinados horarios del día.

2. Las ciudades promoverán la eliminación de barreras arquitectónicas para la implementación del equipamiento

RC: 97615

Disponible: https://www.nucleodoconhecimento.com.br/ley/asistencia-prioritaria 
necesario para el sistema de movilidad y circulación y la adaptación de todos los edificios públicos o públicos, lugares de trabajo, para garantizar la accesibilidad de las personas con necesidades especiales (CARTA MUNDIAL DO DIREITO À CIDADE, 2004, p. 3).

Cabe mencionar que cuando se trata de accesibilidad no se limita al espacio físico donde se instala, es la ciudad en su conjunto la que representa el proceso político, social, económico e intelectual de la sociedad.

En el ámbito de la educación y la salud, se destaca que la inclusión escolar se configura como un derecho del ciudadano garantizado universalmente, destacando como hito de este proceso la Declaración de Salamanca, que hace hincapié en la educación inclusiva, siguiendo las convenciones y los derechos humanos, dirigida a la niñez y la adolescencia, presentando aquí, las principales, como mérito de conocimiento básico de la materia.El documento lleva el nombre de una Conferencia Mundial sobre Educación Especial en Salamanca en 1994, que tuvo como objetivo reestructurar la reforma de las políticas de acuerdo con la inclusión, afirmando que:

"Todo niño tiene un derecho fundamental a la educación, y se le debe dar la oportunidad de alcanzar y mantener el nivel adecuado de aprendizaje, todo niño tiene características, intereses, habilidades y necesidades de aprendizaje que son únicas, los sistemas educativos deben ser designados y los programas educativos deben ser implementados a fin de tener en cuenta la amplia diversidad de tales características y necesidades, las personas con necesidades educativas especiales deben tener acceso a la escuela regular, que debe ser capaz de apoyarlos dentro de una pedagogía centrada en el niño, capaz de satisfacer tales necesidades, las escuelas regulares que tienen esa orientación inclusiva son el medio más eficaz de combatir las actitudes discriminatorias mediante la creación de comunidades acogedoras, la construcción de una sociedad inclusiva y el logro de la educación para todos; además, esas escuelas proporcionan una educación eficaz a la mayoría de los niños y mejoran la eficiencia y, en última instancia, el costo de la eficacia de todo el sistema educativo (...)" Así cita el documento (ONU, 2010, p. 78).

$\mathrm{RC}: 97615$

Disponible: https://www.nucleodoconhecimento.com.br/ley/asistencia-prioritaria 
Esta proclamación nos pone en la obligación de ofrecer y brindar oportunidades para niños, niñas y adolescentes programas específicos y de evaluación a medida, asegurando el pleno desarrollo y desarrollo del potencial de cada individuo. Para ello, se deben considerar las readaptaciones del Currículo y estar contemplando la garantía de la ley.

Se trata de un acuerdo internacional sobre los derechos de los niños, niñas y adolescentes. Considerando que, de conformidad con los principios proclamados en la Carta de las Naciones Unidas, el reconocimiento de la dignidad inherente y de los derechos iguales e inalienables de todos los miembros de la familia humana es el fundamento de la libertad, la justicia y la paz en el mundo y teniendo presente que los pueblos de las Naciones Unidas reafirmaron en su Carta su confianza en los derechos humanos fundamentales y en la dignidad y el valor de la persona humana y han determinado promover el progreso social y mejores niveles de vida con mayor libertad.

La Política Nacional de Educación Especial (PNEE) en la Perspectiva de la Educación Inclusiva (PEI) (2008) destaca la necesidad de enfrentar la segregación de los estudiantes en el ámbito escolar y propone una educación especial que se desarrolle de manera complementaria, reafirmando el sistema educativo único.

En este contexto, los derechos humanos son universales y ningún ciudadano puede ser excluido por ningún motivo por sus condiciones físicas, mentales, o por color, raza, costumbre o clase social, por lo tanto, corresponde a las autoridades desarrollar políticas públicas para atender a estas personas por igual.

Así, reconociendo que las personas con discapacidad tienen prioridades, entre ellas, de atención preferencial, rápida e individualizada, realizan el goce de los derechos fundamentales sellados en la Constitución Federal de 1988. Sin embargo, debe aclararse que, al tratarse de un derecho muy personal, este derecho debe ejercerse en beneficio de la persona con discapacidad, o por personas que se encuentren en

RC: 97615

Disponible: https://www.nucleodoconhecimento.com.br/ley/asistencia-prioritaria 
condición de vulnerabilidad, en virtud de la ley federal 10.048, del 8 de noviembre de 2000[8], que consagró la prioridad de atención a las personas que especifica: personas con discapacidad, mujeres embarazadas, mujeres lactantes, personas acompañadas de niños en sus vidas, además de los ancianos.

También se evidencia que la condición personal del partido no es el punto culminante principal del Estatuto de la Persona con Discapacidad, lo que se busca es la atención preferencial, inmediata e individualizada de la parte vulnerable, en nuestro estudio, la persona con discapacidad en Notarios.

\section{SITUACIÓN DE LAS PERSONAS CON DISCAPACIDAD Y PRINCIPIO DE PRELACIÓN DEL REGISTRO DE BIENES INMUEBLES}

En el contexto de los servicios notariales y registrales, además del cumplimiento de los principios básicos de la administración pública, es necesario que los notarios y registradores también cumplan con los principios considerados específicos de estas actividades. Es importante entender que los principios son maleables, dado que se adaptan a las circunstancias históricas y sociales que atraviesan.

Los principios aplicados a los servicios registrales implican las actuaciones a realizar a lo largo del proceso registral, desde la inscripción hasta la comisión rogatoria, estando relacionadas con el Derecho Inmobiliario. El principio de registro, según Carvalho (2011), es el inicio del proceso, siendo responsable de la constitución, transmisión, modificación o extinción de los derechos en ris. Es, por tanto, el registro de actos que alteran o extinguen cualquier acto de registro.

El principio de publicidad ya mencionado como principio básico de la administración pública todavía se considera, y los registradores deben hacer públicos los registros realizados dentro de sus Notariotories. Según Ceneviva (2008), la publicidad como

RC: 97615

Disponible: https://www.nucleodoconhecimento.com.br/ley/asistencia-prioritaria 
principio de la actividad registral tiene como objetivo cumplir su triple función, que es transmitir el registro al conocimiento de terceros, informar sobre los bienes y derechos de las personas que reciben beneficios derivados del acto de registro, sacrificando, incluso parcialmente, su derecho a la privacidad y la intimidad y promoviendo actos con fines estadísticos, interés nacional o supervisión pública.

El principio de presunción de verdad aplicado a los servicios registrados es también el resultado de la fe pública que se les concede junto con la delegación de la función. Vasconcelos y Cruz (2000) aclaran que la fe pública debe extenderse a todos los actos realizados en el ámbito de los servicios registrales, respondiendo positivamente a la existencia de derechos reales. Así, siempre se asume que todo lo que está inscrito en el registro de la propiedad inmobiliaria es cierto hasta que se demuestre lo contrario.

A su vez, el principio de prelación se ocupa de la cuestión del orden de las inscripciones en el registro de bienes inmuebles, y el registrador debe considerar el orden cronológico de presentación de los títulos, de acuerdo con el art. 186 de la Ley № 6.015/1973. Antunes (2005) señala que es el orden cronológico el que debe determinar la prioridad del título y la preferencia del derecho real.

El principio de especialidad o determinación de registros trae que el registro debe hacerse para que la descripción del inmueble sea precisa y con sus características peculiares, como registro, número de pedido, fecha, identificación del inmueble, enfrentamientos, ubicación y área. Además, también es necesario incluir datos de su titular como nombre, domicilio, nacionalidad, estado civil, profesión, número de registro general $(R G)$ y, en caso de persona jurídica, debe estar incluido en la sociedad social y el número del Registro Nacional de Personas Jurídicas (CNPJ). La correcta descripción de estos datos es fundamental para dotar de seguridad jurídica a los actos realizados (ANTUNES, 2005).

RC: 97615

Disponible: https://www.nucleodoconhecimento.com.br/ley/asistencia-prioritaria 
Continuar con la descripción de los principios de los servicios registrados tiene el principio de calificación, legalidad o legitimidad que, según Antunes (2005), el registrador debe examinar el título presentado considerando la forma, validez y cumplimiento de la ley. Galiani (1995) también menciona que incluso para examinar el título que se le ha dado, el registrador debe acogerse a la legislación, no pudiendo ir más allá de los límites establecidos por la ley, y debe analizar solo los aspectos formales de la misma.

El principio de continuidad también forma parte de la lista de principios aplicados a los servicios de registro, siendo destacado por Antunes (2005) como uno de los fundamentos de estos servicios. Sobre la aplicación de este principio, Balbino Filho (2001) aclara que trae consigo la obligación de continuidad del registro, manteniendo la conexión entre los diferentes negocios que llegaron a modificar la situación jurídico-real. Así, todos los cambios que se produzcan en el título deberán quedar registrados en el mismo documento, conservando la información anterior.

Por último, está el principio de la instancia o rogación, que se refiere a la acción adoptada por el registrador sobre la base de la solicitud de las partes. Según Balbino Filho (2001), el principio de instancia o rogación se refiere a la solicitud de cualquier acto registral, y debe ser simple, independiente de una manera especial, y puede ser expreso o tácito. Expresado cuando es claramente expresado por las partes y tácito cuando el registrador puede identificar la voluntad de las partes relatando su experiencia.

En vista de lo anterior, los servicios de registro deben realizarse de conformidad con los principios mencionados, y no se puede olvidar que los principios básicos de la administración pública deben considerarse en todas las actividades realizadas por los registradores en el ámbito de sus funciones.

Las discusiones sobre el principio de prioridad del registro de bienes raíces han sido un tema de discusión, tanto que es posible identificar casos juzgados que

RC: 97615

Disponible: https://www.nucleodoconhecimento.com.br/ley/asistencia-prioritaria 
consideran conflictos con derechos de ciertos públicos. Lago (2016) cita el otorgamiento de prioridad en el cuidado de abogados y el otorgamiento de cuidados prioritarios a los ancianos, ambos del Tribunal de Registros de São Paulo - SP. En la primera fue denegada debido a la disposición legal específica sobre la ley 8.906/1994 - Estatuto del Colegio de Abogados de Brasil, y la violación del orden de precedencia, sin embargo, se hizo una recomendación para otorgar atención prioritaria en los casos en que los notarios y jueces registrados, bajo criterios prudentes, fuera necesario.

En el segundo caso, los magistrados utilizaron los criterios definidos por la Ley 6.015/1973 y el Código Civil, afirmando que la orden presentada debe seguirse estrictamente. Con ello, se dejó el entendimiento de que se otorgaría atención prioritaria a las personas mayores en la provisión de certificados o en la entrega de documentos, pero no en la entrada de títulos que pudieran generar prioridad (LAGO, 2016).

A partir de esto, es posible tomar esta comprensión también en el caso de las personas con discapacidad, ya que su Estatuto también prevé el derecho a la atención prioritaria. Se constató que, a juicio de los tribunales inscritos, prevalece la disposición específica de la Ley № 6.015/1973 en relación con el derecho de atención prioritaria de determinados públicos, ya que se trata de un derecho material de prelación, entendiéndose que otorgar la atención prioritaria fuera de los requisitos del art. 186 de la Ley № 6.015/1973, representaría un reconocimiento innegable de la causa extralegal, lo que comprometería el servicio al derecho a la igualdad, premisa también del Estatuto de la Persona con Discapacidad.

El principio de prioridad se establece en las artes. 182 y siguientes, de la Ley № 6.015/73. Se menciona, por ejemplo, su incidencia sobre la hipoteca y los actos que la rodean, aunque redundantes, también está contenida en el Código Civil, en el art. 1493, in verbis: "Los registros y avales deberán seguir el orden en que se soliciten,

RC: 97615

Disponible: https://www.nucleodoconhecimento.com.br/ley/asistencia-prioritaria 
verificando el de su numeración sucesiva en el protocolo". Por lo tanto, no hay como solicitud de una persona discapacitada su solicitud cumplida ante aquellos que le sucedieron en una Oficina de Registro. En este sentido Afrânio Carvalho (2011):

(...) en un concurso de derechos reales sobre una propiedad, no todos ocupan el mismo rango, sino que se gradúan o califican por una relación de precedencia basada en el orden cronológico de su aparición: prior tempore potior jure. Dependiendo del tiempo en el que surjan, los derechos toman posición en el registro, prevaleciendo los previamente establecidos sobre los que vienen después. (CARVALHO, 2011, p. 216).

Se aclara que los títulos que generen derecho de prelación deberán ingresar al Registro de la Propiedad Inmobiliaria, previa liberación en el Libro № 1 - Protocolo, de acuerdo con el estricto orden de presentación descrito en la Ley de Registros Públicos. Por esta razón, cualquier derecho a la atención preferente por discapacidad, edad, sexo no permite, en términos de estos títulos, ser recibido antes que otros que ya han entrado en las instalaciones del servicio en primer lugar. Aplicando el principio de prioridad registral, se debe inscribir un título, en primer lugar, de acuerdo con el número de protocolo más bajo, "deprimiendo el registro de los presentados posteriormente, por el período correspondiente al menos a un día hábil" (Ley 6.015/73, art. 191). Sin embargo, aunque no se aplica el principio de prioridad a los discapacitados, en ambos casos los títulos deben registrarse.

Para resolver el problema, Lago (2016, p. 316) sugiere "un sistema de un sistema compuesto por un dispositivo proveedor de contraseñas con ciertas características y dos libros de protocolo simultáneos, uno preliminar y otro definitivo". Sin embargo, se cree que el problema va más allá, al no ser suficiente para su solución, considerando la autonomía del sistema registral y la intención de promulgar el Estatuto de la Persona con Discapacidad, se entiende que la atención prioritaria en este caso no debe ocurrir, de lo contrario perjudicaría el derecho a la igualdad.

RC: 97615

Disponible: https://www.nucleodoconhecimento.com.br/ley/asistencia-prioritaria 


\section{CONCLUSIÓN}

Los servicios notariales y registrales fueron abordados en este estudio considerándolos en su actividad realizada por la esfera privada por delegación del Poder Público, teniendo en cuenta estar enfocados al interés social, por tanto, debido a la obediencia a los principios generales de la administración pública, además de principios propios de estas actividades que deben observarse en cada acto.

Además de la obediencia a principios específicos de estas actividades, que son el de la inscripción, la publicidad, la presunción de verdad, la prioridad, la de la especialidad o determinación de los registros, la de calificación, legalidad o legitimidad, la de continuidad e instancia o rogación, así como la de fe pública, que una de las principales mencionadas en la jurisprudencia.

El tema fue abordado desde la perspectiva de que, si bien los derechos de las personas con discapacidad están garantizados en la Constitución Federal, la realidad revela una gran distancia entre los derechos formales y su efectividad, verificando que existieran numerosas políticas públicas dirigidas a las personas con discapacidad a lo largo de la historia en busca de accesibilidad, movilidad e igualdad de derechos, integrándolos en la sociedad, sin embargo, es evidente que aún queda un camino importante por seguir para que sus derechos se efectíen de manera efectiva.

Dentro del sistema de registro, se encontró que existe un conflicto entre sus disposiciones del principio de prioridad de registro y el Estatuto de la Persona con Discapacidad que prevé la atención prioritaria a este público. Resulta que en este sistema se enfocan los derechos materiales, por lo tanto, considerar el Estatuto de la Persona con Discapacidad para la atención prioritaria tendría consecuencias como la posibilidad de eludir o defraudar el sistema legal vigente en el país.

$\mathrm{RC}: 97615$

Disponible: https://www.nucleodoconhecimento.com.br/ley/asistencia-prioritaria 
Así, de decisiones similares tomadas por los registros de São Paulo, se percibió que la disposición específica de la Ley № 6.015/1973 prevalece en relación con el derecho de atención prioritaria de ciertos públicos, ya que se trata de un derecho material de prioridad, entendiéndose que otorgar la atención prioritaria fuera de los requisitos del art. 186 de la Ley № 6.015/1973, representaría un reconocimiento innegable de una afrenta a los derechos reales de los ciudadanos, que comprometería el servicio al derecho a la igualdad, una premisa también del Estatuto de las personas con discapacidad.

Finalmente, como forma de responder a la pregunta que es la guía de este ensayo, se acepta que la garantía del mecanismo de prioridad registral no contrasta con la facultad generalmente establecida en el Estatuto de las personas con discapacidad. Las reglas de esto no se imponen a las reglas de la Ley 6.015/1973. Se ocupan de tales diplomas en diferentes situaciones. Es decir, vale la norma protectora hasta el límite de que no sea excluida por otro, de orden público, que profana, a los interesados, la prioridad registral y en el extremo remoto la preferencia y definición de los derechos reales.

\section{REFERENCIAS}

ANTUNES, Luciana Rodrigues. Introdução ao Direito Notarial e Registral. Jus Navigandi, Teresina, ano 9, n. 691, 2005.

BIANCHETTI, Lucídio; FREIRE, Ida Mara (orgs.). Um olhar sobre a diferença: interação, trabalho e cidadania. 6. ed. São Paulo: Papirus. 2007.

BRASIL. Constituição da República Federativa do Brasil, de 05 de outubro de 1988. Brasília, 1988. Diário Oficial da União. Disponível em: http://www.planalto.gov.br/ccivil_03/Constituicao/Constituicao.htm Acesso em: julho.2021.

RC: 97615

Disponible: https://www.nucleodoconhecimento.com.br/ley/asistencia-prioritaria 
BRASIL. Decreto no 5.296 de 2 de dezembro de 2004. Diário Oficial da União, 3 dez. 2004. Disponível em: http://www.planalto.gov.br/ccivil_03/_ato20042006/2004/decreto/d5296.htm . Acesso em: 25 jul. 2021.

BRASIL. Lei n. 13.105, de 16 de março de 2015. Disponível em: <https://www.planalto.gov.br/ccivil_03/_ato2015-2018/2015/lei//13105.htm> Acesso em: jul.2021.

BRASIL. Lei o 10.406, de 10 de janeiro de 2002. Institui o Código Civil. Diário Oficial da União: seção 1, Brasília, DF, ano 139, n. 8, p. 1-74, 11 jan. 2002.

BRASIL. Lei ㄲo. 10.048, de 08 de Novembro de 2000. Diário Oficial [da República Federativa do Brasil], Brasília. Disponível em: https://www.presidencia.gov.br/ccivil_03/Leis/L10048.htm . Acesso em: 30jul.2021.

BRASIL. Lei №. 10.098, de 19 de Dezembro de 2000. Diário Oficial [da República Federativa do Brasil], Brasília. Disponível em: https://www.presidencia.gov.br/ccivil_03/Leis/L10098.htm . Acesso em: 30jul.2021.

BRASIL. Presidência da República. Lei 7.853 de 24 de outubro de 1989. Disponível em:http://www.planalto.gov.br/ccivil_03/leis/l7853.htm - Acesso em 26/07/2021.

CARTA Mundial do Direito à Cidade. Fórum Social das Américas - Quito - Julho 2004; Fórum Mundial Urbano - Barcelona - Setembro 2004; V Fórum Social Mundial - Porto Alegre - Janeiro 2005. Disponível em: Acesso em: 30 jul. 2021.

CARVALHO, Afrânio de. Registro de imóveis. Rio de Janeiro: Editora Forense, 2011.

CENEVIVA, Walter. Lei dos notários e registradores comentada. São Paulo: Saraiva, 2008.

RC: 97615

Disponible: https://www.nucleodoconhecimento.com.br/ley/asistencia-prioritaria 
CLEMENTE, Carlos Aparício. Lei de cotas para o trabalho de pessoas com deficiência: Análise e fundamentação dos principais argumentos favoráveis e contrários ao seu cumprimento. 2015.

GALIANI, Luiz Antônio. Os princípios basilares do fólio real. RJ n. 212, jun/95.

GOFFMAN, Erving. Estigma: notas sobre a manipulação da identidade deteriorada. $4^{a}$. ed. Rio de Janeiro:LTC, 2008.

GUGEL, Maria Aparecida. Benefício da prestação continuada e trabalho: Mudanças da Lei № 12.470, de 31 de agosto de 2011. Disponível em: Acesso em jul.2021.

KOYAMA, D. B. Os reflexos da lei 13.146/2015 - Estatuto da Pessoa com Deficiência - no sistema jurídico brasileiro. Universidade Presbiteriana Mackenzie, São Paulo, 2017.

LAGO, Ivan Jacopetti do. O atendimento prioritário da Lei Federal 13.146/2015 (Estatuto da Pessoa Com Deficiência) e o princípio da prioridade do registro de imóveis.Revista de Direito Imobiliário,São Paulo, ano 39, v.80, jan-jun.2016.

LORENTEZ, Lutiana Nacur. A norma da igualdade e o trabalho das pessoas portadoras de deficiência. São Paulo: LTr, 2006.

MAINIERI, Tiago; ROSA, Elisa Costa Ferreira. Comunicação pública, cidadania e democracia-algumas reflexões. Revista Comunicação Midiática, v. 7, n. 1, p. p. 192-206, 2012.

ORGANIZAÇÃO DAS NAÇÕES UNIDAS (ONU). Declaração de Direitos do Deficiente Mental - 1971. Aprovada pela resolução n. A/8429 da Assembleia Geral da ONU de 22 de dezembro de 1971. Disponível em: http://www.direitoshumanos.usp.br/index.php/Direito-dos-Portadores-de-

RC: 97615

Disponible: https://www.nucleodoconhecimento.com.br/ley/asistencia-prioritaria 
Defici\%C3\%AAncia/declaracao-de-direitos-do-deficiente-mental.html. Acesso em 27/07/2021.

SILVA, C. H. R. Teoria das Incapacidades. [online]. 2008. Disponível em: <http://www.ribeirodasilva.pro.br/teoriadasincapacidades.html> Acesso em: jul.2021.

VASCONCELOS, Julenildo Nunes; CRUZ, Antônio Augusto Rodrigues. Direito notarial: teoria e prática. [S.I.] Juarez de Oliveira, 2000.

\section{APÉNDICE - NOTA DE REFERENCIA}

4. Conjunto de medidas legales para proteger situaciones en proceso de configuración, modificación o extinción.

5. Conjunto de medidas legales propuestas para mantener las situaciones establecidas

6. Establece normas generales y criterios básicos para promover la accesibilidad de las personas con discapacidad o movilidad reducida, y prevé otras medidas.

7. Regula las Leyes 10.048 , de 8 de noviembre de 2000 , que da prioridad a la atención a las personas que especifica, y 10.098, de 19 de diciembre de 2000, que establece normas generales y criterios básicos para la promoción de la accesibilidad para personas con discapacidad o movilidad reducida, y prevé otras medidas.

8. Da prioridad a la atención a las personas que especifica, y proporciona otras medidas.

Enviado: Julio de 2021.

Aprobado: Septiembre de 2021.

RC: 97615

Disponible: https://www.nucleodoconhecimento.com.br/ley/asistencia-prioritaria 